\title{
ICT in China: A strong Force to Boost Economic and Social development
}

\author{
Xinxiang CHEN, Jiaqing GAO, and Wenda TAN \\ Capinfo Company Limited \\ xxchen@capinfo.com.cn
}

Key words: Development strategy, industrialization and informatization, liberalization, ICT and economic growth, social economy.

Further development of science and technology in the 21 st century, especially IT and life sciences, will exert a profound influence on politics, economies and cultures around the world. In the opinion of experts, digitization in the early years of the 21 st century will give new impetus to IT development: integrated circuits will enter into a new phase of integrated system development, transmission capacity of the DWDM (Dense Wavelength Division Multiplexing) communication system will be improved dramatically, and the technology and capacity of personal mobile communications and the Internet will also be enhanced to a great extent. The constant development of intellective and technological innovations, as well as combinations of material object production and intellectual production, hardware and software manufacture, traditional economies and IT technologies, will form a strong force to boost economic and social development in the 21 st century.

\section{ICT DEVELOPING STRATEGY IN CHINA}

President Jiang Zemin, delivering a keynote speech during the opening ceremony of the 2000 World Computer Congress, emphasized the importance of IT for the country's economic development and social informatization. China's ICT strategy is: utilizing IT in the process of industrialization to enhance industrialization levels, utilizing IT in the 
process of informatization to reconstruct traditional industries, using IT to propel industrialization itself and, lastly, striving to realize "great-leapforward" development and better use of IT for human well-being, taking advantage of China's position as a late starter. This implies that the government regards ICT as a strategic measure for national economic development. Further rapid growth of information and communication industries would make them pillar industries in the Chinese economy and an accelerator and amplifier for the development of other industries.

The above strategy has been formally integrated into state policies. It is clearly stated in the $16^{\text {th }}$ Communist Party Congress that "centering on economic construction and liberalizing and developing social productive forces is essential to build a comprehensively well-off society. According to the latest developing trend of the world economy and technologies as well as the situation in the new phase of economic development of China, the main tasks in economic development and reforms in China for the first twenty years of this century are: perfecting the socialist market economic system; boosting strategic adjustments to economic structures, generally realizing industrialization; a greater effort to promote informatization; speeding up modernization; maintaining the sustainable and healthy development of the national economy and constantly improving the people's life". The Chinese government is attaching much importance to the IT industry and is engaged in a great effort to boost the national economy and social informatization, centering on the grand objectives laid down in the $16^{\text {th }}$ Communist Party Congress.

Realizing that China is a developing country facing the arduous tasks of achieving both industrialization and informatization at the same time, we established the following development strategy: to search for a new industrialization mode with high technological content, sound economic profits, lower resource consumption, reduced environmental pollution and adequate use of human resources; to enforce the strategies of rejuvenating the country through sciences, education and sustainable development; to make use of IT to propel industrialization and, in turn, stimulate informatization; to utilize IT in the process of industrialization, in order to enhance industrialization levels, as well as employing IT in the process of reconstructing traditional industries through informatization; to make use of our advantages as a late starter, in order to develop IT by leaps and bounds; and meanwhile, give a priority to IT industry, applying IT in all aspects of social and economic fields. 


\section{IMPACT OF WTO ACCESSION ON ICT POLICIES AND ADMINISTRATION IN CHINA}

With the unparalleled challenges and opportunities brought about by China's accession to WTO, the Chinese telecom market will become a focus of future global competition. Figure 1 provides the basic framework and schedule for China's gradual liberalization of the telecom service market, in accordance with China's accession commitments.

Figure 1: Gradual Liberalization of the Chinese Telecom Market After China's

Accession to WTO

\begin{tabular}{|c|c|c|c|}
\hline Type of Services & Time & $\begin{array}{l}\text { Liberali- } \\
\text { zation } \\
\text { Ratio }\end{array}$ & Cities to be liberalized \\
\hline \multirow{3}{*}{$\begin{array}{l}\text { Value-added } \\
\text { services }\end{array}$} & 2001 & $30 \%$ & Beijing, Shanghai, Guangzhou \\
\hline & 2002 & $49 \%$ & $\begin{array}{l}\text { Beijing, Shanghai, Guangzhou, } \\
\text { Chengdu, Chongqing, Dalian, } \\
\text { Fuzhou, Hangzhou, Nanjing, } \\
\text { Ningbo, Qingdao, Shenyang, } \\
\text { Shenzhen, Xiamen, Xi'an, } \\
\text { Taiyuan, Wuhan }\end{array}$ \\
\hline & 2003 & $50 \%$ & The whole country \\
\hline \multirow{3}{*}{$\begin{array}{l}\text { Mobile data } \\
\text { services }\end{array}$} & 2002 & $25 \%$ & Beijing, Shanghai, Guangzhou \\
\hline & 2004 & $35 \%$ & $\begin{array}{l}\text { Beijing, Shanghai, Guangzhou, } \\
\text { Chengdu, Chongqing, Dalian, } \\
\text { Fuzhou, Hangzhou, Nanjing, } \\
\text { Ningbo, Qingdao, Shenyang, } \\
\text { Shenzhen, Xiamen, Xi'an, } \\
\text { Taiyuan, Wuhan }\end{array}$ \\
\hline & 2006 & $49 \%$ & The whole country \\
\hline \multirow[t]{3}{*}{ Fixed services } & 2004 & $25 \%$ & Beijing, Shanghai, Guangzhou \\
\hline & 2006 & $35 \%$ & $\begin{array}{l}\text { Beijing, Shanghai, Guangzhou, } \\
\text { Chengdu, Chongqing, Dalian, } \\
\text { Fuzhou, Hangzhou, Nanjing, } \\
\text { Ningbo, Qingdao, Shenyang, } \\
\text { Shenzhen, Xiamen, Xi'an, } \\
\text { Taiyuan, Wuhan }\end{array}$ \\
\hline & 2007 & $49 \%$ & The whole country \\
\hline
\end{tabular}


To confront these challenges, ICT governmental organs and the ICT circle have made some adjustments in the areas of laws and regulations, organization structures and regulatory roles.

During recent years, obvious progress has been made in telecom legislation and the regulatory system. In 2000, the State Council promulgated the Telecommunications Regulation of the People's Republic of China, which is the major regulation for defining juristic relationships among parties with different interests in the telecom sector. Another instrument of equal importance is the Radio Administrative Regulation jointly published by the State Council and the Central Military Committee in 1993. In the past several years, competent authorities, such as the Ministry of Posts and Telecommunications and the Ministry of the Information Industry successively enacted many rules and regulations, involving many aspects such as: Internet connections, authentication of equipments for accessing networks and Internet access service. At present, we hope that the Telecommunication Act will, after multiple rounds of negotiation, be adopted as soon as possible, in order to provide a more stable legal framework for the Chinese telecom industry, one which is beneficial to investment, commercial development and technical advances.

Currently, the Ministry of the Information Industry acts as a decision developer as well as a regulator, mainly responsible for developing and enforcing development and regulatory policies relating to information and communications policies (ICT), covering the electronic industry and the communication service sector. Generally speaking, the objective of Chinese telecom policies and regulatory system is to promote the ICT industry in China and provide a fair competitive environment for all companies entering the Chinese market, based on the principle of market orientation and compliance with the WTO Agreement. As a regulatory organ, the Ministry of the Information Industry is independent from any telecom operators, and administers the information sector according to principles of fairness, transparency, independence, specialty, consistency and accountability. In terms of organizational construction and competence development, telecom administrative bureaus are set up within the Ministry of the Information Industry, and there is a telecom bureau in each province that is directly accountable to the Ministry. This kind of vertical incorporated organization structure is quite unique among the sector regulatory systems of China. 


\section{ICT POLICIES ENCOURAGE COMPETITION IN THE TELECOM SECTOR}

Considering current competitive situation and opportunities brought about by technical advances, the telecom circle and policy researchers have reached a consensus that more competition should be introduced into the Chinese telecom sector. Quite especially since China's accession to WTO, the country should open telecom services to enterprises under different ownerships as soon as possible.

Figure 2: Market Shares of the Turnover of Major Telecom Operators in China in 2002

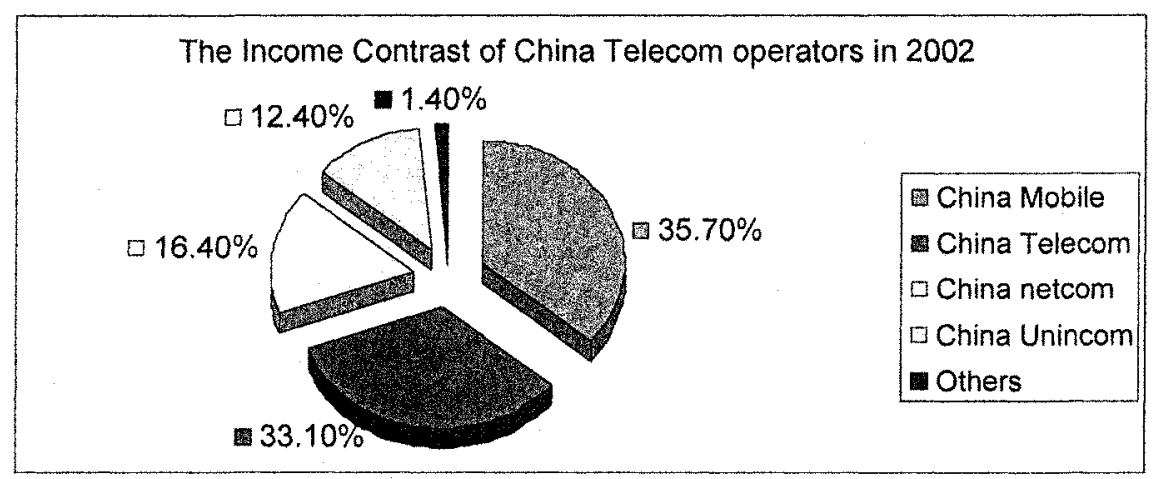

As a public utility, the telecom sector has a certain natural monopoly. As a result, telecom service sectors in a majority of countries of the world were owned and operated by the government for most of the last century, and China was no exception. In making the transition from planned economy to market economy in China, most sectors have undergone drastic market-oriented reforms since the beginning of the 1980's, reforms which have been quite effective and fruitful. However, due to its natural monopoly and its strategic importance in the economy, market-oriented reforms in the telecom sector fell behind other sectors. The establishment of China Unicom ended the monopoly status of the telecom department subsidiary to the Ministry of Posts and Telecommunications. Compared with European countries such as Germany and France, such reform in the telecom sector was relatively early. Introduction of competition to the telecom sector has exerted an obvious influence on the attraction of investment, technical innovation, reduction of operational costs and the improvement of service quality, as well as has greatly boosting the development of the Chinese telecom sector, in particular mobile communications. 
Confronted with new challenges after China's accession to WTO, the Chinese government conducted in-depth reforms in telecom systems in 1998 , including the separate operation of posts and telecom, separation of telecom enterprises from government organs, company-oriented reorganization of enterprises and the establishment of the Ministry of the Information Industry, etc.

In 1998, the former Ministry of Posts and Telecommunications completed the separation of postal operations from telecom operations, as well as the separation of telecom enterprises from governmental organs. China Telecom, China Unicom and other telecom enterprises became real commercial entities via company-oriented reorganization. China successfully introduced competition into the telecom sector in a period shorter than ten years. Up to now, China has six basic telecom operators namely: China Telecom, China Netcom, China Mobile, China Unicom, China Railcom and China Satellite Communications, and has over 4400 companies offering telecom value-added services and non-basic telecom services. China Unicom operates two mobile communication networks: a GSM network with 70 million users and a CDMA (Code-Division Multiple Access) with 15 million users (December 2003). China Mobile is now the mobile communication operator with the most users in the world, mainly providing vocal and data mobile communication services. Its users currently exceed 140 million. China Telecom and China Netcom are two major providers of fixed telephone services. Meanwhile China Railcom and China Satellite Communications have in recent years marked their fastest development.

\section{IMPACT OF ICT ON THE NATIONAL ECONOMY}

In China, great things have been achieved in informatization construction in recent years. ICT has an increasingly significant influence on the national economy and social life as the share and importance in the national economy of industries involving ICT has gradually advanced year by year. Added value in IT represented 4.66\% of GDP in 1998, while in 1993 the ratio was $2.45 \%$. IT industry growth contributed $11.00 \%$ to the expansion of GDP in 1998, while in 1993 its contribution was $4.22 \%$. In 1999, the contribution ratio of IT output value to GDP exceeded $10 \%$, while within the $7.1 \%$ of growth, the IT industry contributed approximately $1 \%$. The export value of IT products accounted for $20 \%$ of total export value of China. The IT industry has maintained an average growth rate of $32 \%$ each year in the last 10 years, nearly $18 \%$ higher than the average growth rate of all industries combined in the same period. 
The Chinese communication sector has kept up such high-speed consecutive annual expansion throughout more than a decade, and already as far back as 1984 its growth had begun to pull ahead of that of the national economy. From 1989 till 2001, the business income in the communication sector grew $36 \%$ each year on average, with the highest growth exceeding $50 \%$.

The percentage of the telecom service sector in all other service sectors increased by $2.9 \%$, from $3.8 \%$ in 1995 to $6.7 \%$ in 2000 . Such rapid development has promoted the manufacture of communication equipment. Many big multinational communication equipment suppliers entered the Chinese market and set up their own equipment manufacturing bases in China. Yet some domestic equipment suppliers such as Huawei, ZTE and CATT have emerged in this severely competitive environment. Based on a better understanding of domestic telecom markets, these elite domestic companies are thriving, both in competition and cooperation with multinational firms, representing a greater and greater market share and expanding abroad. With regard to the contribution of ICT to socio-economic development, the electronics industry (i.e. ICT and hardware, including communication equipment) contributed $4.9 \%$ to manufacturing sector output in 1995, while in 2001 the ratio reached $8.02 \%$, representing an increase of $3.12 \%$.

Under the $10^{\text {th }}$ national five-year plan, our industry objective is: the gross output value in the electronic industry is to reach RMB2500 billion Yuan, with an average annual growth rate of $20 \%$; sales revenue is to reach RMB 1500 billion Yuan, an increase of $20 \%$; and the productivity of all those working in the IT industry is to reach RMB180,000 Yuan per capita per annum (calculated on the basis of added value).

\section{ICT AND PEOPLE'S LIFE IN CHINA}

China's ICT policies highlight the principle "putting people first and serving the people". As described by the International Telecommunications Union (ITU), the information-based society is comprised of two parts: the social economy and the industries (see Figure 3). 
Figure 3: Correlations among various parts of information-based society (ref.7)

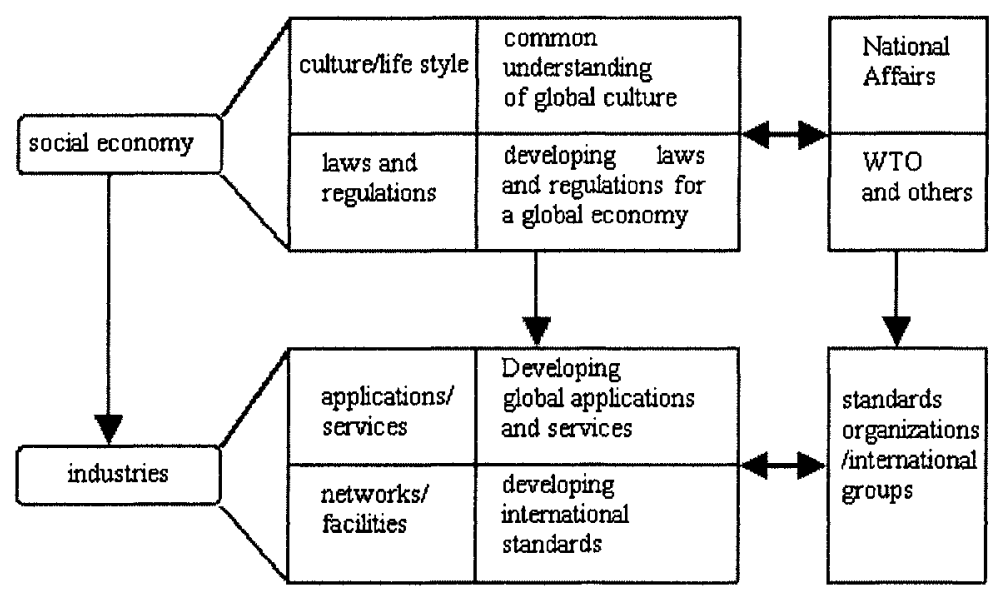

"Social economy" includes: establishing new life styles (such as online shopping, virtual reality, etc.), creating new cultural and artistic patterns (such as multimedia books, distance music listening, etc.), developing laws, regulations and rules (such as medical care law for telemedicine) and so on. "Industries" involves: the creation of new applications and services (such as eCommerce and video services), setting up of information networks (such as telecom networks, cable TV networks and satellite networks) and the manufacture of equipment (such as terminals, transmission systems and servers). In this way the information-based society will be one in which people are put first and cultures and the environment are better protected. In such a society, the keywords will be: humanity, environment and information - as each and every person becomes able to create, acquire, use and share information and knowledge, and individuals, communities and the wider community in every country will be in a position to exercise their potential to the fullest, to boost sustainable development and the improvement of life quality.

Realization and development of the information-based society is inseparable from the ICT and IT industry. In the $21^{\text {st }}$ century, humans will create new modes of working, management, trade, finance, communications, education, medical care, etc., as well as new modes of consumption and lifestyle. Thus ICT will inevitably take a lead in the process of sustainable development.

According to the Statistical Survey on Internet Development in China, published by China Internet Network Information Center ("CNNIC") in January 2004, the number of internet users, computer hosts, domain names 
registered under ".cn" and websites in China reached 79.5 million, 30.89 million, 340,000 and 595,500 respectively, while total bandwidth of leased international connections reached 27,216M. More and more "netizens" log onto the Internet at home, the percentage of these netizens represented $66.1 \%$ of all netizens in China; dial-up is still the dominating method for logon, but broadband users have grown rapidly, reaching 17.40 million. Meanwhile, $32.2 \%$ of netizens $\log$ on for leisure and fun.

"Logon by households" is an important project in the process of community informatization. The overall objective of "logon by households" is: in 2004, community information chain stores are to cover all cities at or above prefecture level in the country; and $20 \%$ of communities in China's major cities are expected to become eCommunities; by 2005, the number of Internet users around the country is supposed to reach 150 million, over $30 \%$ of households will have access to the Internet through various terminals, and $80 \%$ of information flows in the area of urban family and individual life, as well as community services, are expected to be achieved through networks.

eCommunity construction is speeding up in large and medium-sized cities in China. Education and training, culture and entertainment activities, medical consulting, housekeeping services, governmental services and logistics and commercial services based on eCommunity networks are becoming available; more and more websites are providing agricultural information, professional, technical and distance education. ICT is influencing all aspects of people's life not only in major cities, but also in rural areas of China.

With regard to the businesses of China Telecom, in 1990 less than $1 \%$ families in China owned fixed-line telephones. After over a decade years' development, in 2002 over $13 \%$ families owned fixed-lined telephones. China now owns the biggest fixed-line communication network and mobile phone network in the world. By the end of December 2003, the number of fixed telephone and mobile phone users hit 264 million and 269 million respectively.

At the same time, IT applications represented by Golden Taxation, Golden Customs and Golden Card provided a broad range of IT applications; IT applications in companies, such as CAD and CIMS technologies have made obvious progress; and eGovernment, eCommerce, distance education and telemedicine are also undergoing further development.

In a word, ICT has penetrated into all fields of society and is affecting all aspects of people's lives and habits. ICT will bring people into an information-based era, and help them to accommodate to and enjoy this era. A typical example was shown in the way the sudden attack of SARS 
highlighted the value of ICT and communication service providers. Indeed, as SARS prevented people from normal social and interpersonal relations, they chose to keep in touch more by phone and short message services, and began to get used to acquiring information and conducting online education and commercial activities through Internet, some even worked at home through the Internet, becoming real members of the SOHO group.

In conclusion, we have seen, and will continue to see, the alteration and improvement of people's lives through the development of ICT, under the guidance of China's ICT policies. And ICT will certainly have an increasingly significant influence on both economic and social development in China.

\section{REFERENCES}

1. Opening Address by President Jiang Zemin on the $16^{\text {th }}$ World Computer Congress, August 21, 2000

2. Report of the $16^{\text {th }}$ Communist Party Congress of China, by President Jiang Zemin

3. Current Status of Chinese Telecom Industry, by Lin Jintong from Beijing Posts and Telecommunications University

4. Calling for and Taking Actual Measures to Narrow "Digital Gap", by Ma Songde from the Ministry of Sciences and Technologies of China

5. 2003 Statistical Survey on the Internet Development of China, CNNIC

6. Information Technologies and Sustainable Development, by Lei Zhenzhou from Scientific and Technological Information Institute under the Ministry of the Information Industry

7. Information Communication Technology and the Consistent Development, by Lei Zhenzhou, from China communication net (www.cl14.net), 14 ${ }^{\text {th }}$ May 2004. 